\title{
CORRIGENDUM
}

\section{MUTYH, an adenine DNA glycosylase, mediates p53 tumor suppression via PARP-dependent cell death}

S Oka, J Leon, D Tsuchimoto, K Sakumi and Y Nakabeppu

Oncogenesis (2015) 4, e142; doi:10.1038/oncsis.2015.4; published online 23 February 2015

\section{Correction to: Oncogenesis (2014) 3, e121; doi:10.1038/ oncsis. 2014.35}

The authors have identified the following error and wish to issue a corrigendum for this paper.

c

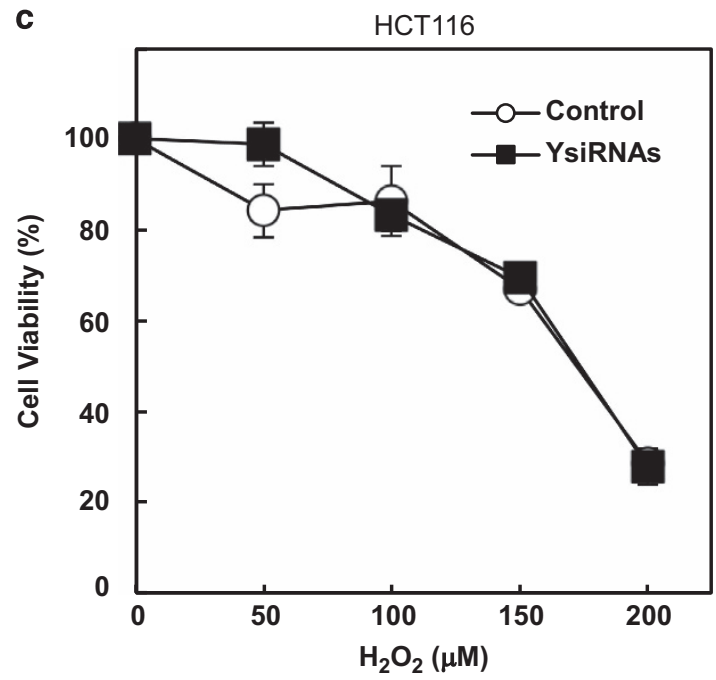

The graph of cell viability in Figure $6 c$ erroneously became a duplication of Figure $6 a$. The correct figure is provided below. This error was unintentionally made during figure preparation upon manuscript revision, and does not alter the results or conclusions of this study in any way.

The authors wish to sincerely apologize to the readers for this error and for any inconvenience that it may have caused.

Figure 6. 